\title{
DIAGNÓSTICO DA UTILIZAÇÃo DE MÉTOdOS DE MELHORIA CONTÍNUA EM CITRÍCOLAS DE LIMÕES
}

\author{
Henrique Pasiani, Rafael Rodrigo Escapa, Tulio de Oliveira, Irene Rodrigues Freitas \\ Centro Universitário do Norte Paulista - UNORP, Curso de Engenharia de Produção, São José do Rio Preto, \\ SP.E-mail: irfreitas@yahoo.com.br.
}

\begin{abstract}
RESUMO
A cadeia citrícola vem conquistando espaço no agronegócio brasileiro e para ter sucesso são necessárias medidas que envolvam mudanças na organização e preocupação em oferecer um produto diferencial no mercado. $O$ objetivo deste estudo foi realizar um diagnóstico do uso de métodos de melhoria contínua em citrícolas de limões. Foi realizada uma pesquisa de campo, quantitativa e qualitativa em três citrícolas existentes a mais de 20 anos no mercado voltadas para a área de preparo e distribuição de limão in natura, ambas localizadas no interior do Estado de São Paulo. As três empresas, são favoráveis às mudanças, no entanto, não utilizam de ferramentas da qualidade, apesar de duas delas mencionar que possuem conhecimento sobre gestão da qualidade. A utilização de métodos de melhorias facilitariam os processos já existentes e ajudaria a dar melhor direção para as citrícolas conquistarem novos mercados.
\end{abstract}

Palavras-chave: qualidade, gestão, melhoria, competitividade, produtividade.

\section{DIAGNOSIS OF USE OF METHODS OF CONTINUOUS IMPROVEMENT IN LEMONS CITRUS}

\begin{abstract}
The citrus chain is conquering space in the Brazilian agribusiness and to succeed measures that envolve changes in the organization are needed to provide a differential product to Market. The aim of this study was to perform a diagnosis of the use of continuous improvement methods in citrus lemons. Field research, quantitative and qualitative in three existing citrus more than 20 years in the targeted market was held for the staging area and distribution of lime in nature, both located in the State of São Paulo. The three companies are supportive of the changes, however, do not use quality tools, although two of them mention that have knowledge about quality management. The use of existing methods of improvements would facilitate the process and help to give better direction to the citrus conquer new markets.
\end{abstract}

Keywords: quality, management, improvement, competitiveness, productivity. 


\section{INTRODUÇÃO}

A citricultura vem conquistando espaço no agronegócio brasileiro com a ampliação do mercado e o aprimoramento da atividade. As frutas que pertencem a este grupo são do gênero Citrus, sendo que as principais espécies são, as laranjas doces, as tangerinas, os limões, as limas ácidas, os pomelos, e outras espécies consideradas menos conhecidas (ZULIAN; DÖRR; ALMEIDA, 2013). No decorrer dos anos, o limão adquiriu importância no setor citrícola paulista e a cultura tem permitido ao agricultor diversificar suas atividades.

A citrícola de limão nada mais é do que o local destinado a receber os produtos provenientes da colheita, e efetuar de maneira satisfatória os procedimentos tais como, seleção, limpeza, sanitização, armazenamento e distribuição do fruto, e estes locais buscam crescer e melhorar a qualidade dos seus produtos e serviços.

Para ter sucesso no setor de citrícola, são necessárias medidas que envolvam mudanças na organização e preocupação com a diferenciação da produção no mercado. A concorrência no mercado nacional e internacional tem levado a importantes mudanças nos negócios agropecuários, que buscam maior eficiência em relação à necessidade de tornar seus produtos mais competitivos (MILOCA et al., 2005), e evidencia a necessidade de repensar a gestão do empreendimento citrícola, envolvendo a determinação de metas, objetivos e estabelecimento de ações.

O que realmente garante a permanência das empresas no mercado é a garantia de sua competitividade, além disso, os consumidores de produtos agroalimentares estão cada vez mais exigentes quanto às características de qualidade do produto que consomem, sejam características nutricionais, sabor, aparência, como os impactos que ele causa ao meio ambiente. Com isso, as citrícolas são obrigadas a adotar uma nova postura diante do consumidor, visando alcançar um diferencial competitivo.

Medidas que pode ser adotadas estão relacionadas com as aplicações de métodos de melhoria contínua que auxiliam os empreendimentos a conquistar novos mercados, uma vez que a qualidade é baseada em todos os fatores inerentes ao produto como, qualidade da matériaprima, dos processos de fabricação, produtos dentro das especificações, entre outros.

É de suma importância que a qualidade esteja sempre vinculada ao desempenho da organização. Diante disso, as empresas devem estabelecer padrões de qualidade não somente do produto em si, mas em todos os níveis da cadeia produtiva. Para que um produto tenha boa aceitação é necessário que haja um controle de qualidade, onde cada processo garanta o processo seguinte a nível desejado de qualidade mensurada (CAMPOS, 1991).

Os métodos de melhoria contínua são vistos nos dias de hoje, como um fator estratégico para a melhoria de competitividade e produtividade. O conceito de qualidade é definido como a adequação do produto ao uso. As empresas que buscam ser competitivas no mercado são importantes manter uma gestão da qualidade, atendendo os requisitos dos clientes quanto a produtos e serviços (CARPINETTI, 2012).

Devido não haver pesquisas em citrícolas relacionadas à aplicação da qualidade, neste contexto, o objetivo deste trabalho foi realizar um diagnóstico do uso de métodos de melhoria contínua em citrícolas de limões localizadas no interior do Estado de São Paulo.

\section{METODOLOGIA}

Trata-se de uma pesquisa de natureza aplicada, com método de abordagem quantitativa e qualitativa, utilizando a entrevista estruturada como instrumento de pesquisa. Foi realizada uma pesquisa de campo, em três citrícolas existentes a mais de 20 anos no mercado voltadas para a produção e distribuição de limão, ambas localizadas no interior do Estado de São Paulo.

Como critério foram escolhidas uma empresa onde seus produtos são destinados apenas para o mercado interno (E1), outra com grande fluxo para o mercado interno e pouco produto 
para exportação (E2) e uma com grande fluxo de produto exportação (E3) e assim, perceber as relações existentes.

O procedimento utilizado para a coleta de dados nessas citrícolas foi a marcação da data para visita, explicação dos objetivos da pesquisa, realização de entrevistas presenciais seguindo sempre o mesmo modelo de questionário.

\section{RESULTADOS E DISCUSSÕES}

Na Tabela 1 estão apresentados os itens gerais aplicados para o diagnóstico da qualidade nas citrícolas de limões, e os respectivos resultados. Através dos resultados obtidos, pode-se perceber que as três organizações, são favoráveis às mudanças, isto mostra que as citrícolas estão preocupadas em buscar de melhorias para os produtos e processos, mas ainda não fazem uso de ferramentas da qualidade, tais como, fluxograma, diagrama de Pareto, diagrama de Ishikawa, folha de verificação e histograma, que auxiliariam na gestão da qualidade.

Os produtores possuem metas e objetivos bem delineados, pois, estes requisitos devem ser atualizados e alterados conforme o mercado e a necessidade das pessoas. A adoção de metas e objetivos factíveis e próximos à cultura organizacional da empresa, além do apoio da alta administração, se faz extremamente importante, pois permitem melhor assimilação pela equipe que não necessita de maior esforço para atingir a meta devido à proximidade com o serviço executados diariamente.

Tabela 01. Itens gerais para diagnóstico da qualidade nas citrícolas.

\begin{tabular}{lccc}
\hline \multirow{2}{*}{ Itens analisados } & \multicolumn{3}{c}{ Citrícola de limão } \\
\cline { 2 - 4 } & E1 & E2 & E3 \\
\hline Favoráveis à mudanças & $\operatorname{Sim}$ & $\operatorname{Sim}$ & $\mathrm{Sim}$ \\
Utilização de ferramentas da qualidade & Não & Não & Não \\
Metas e objetivos bem delineados & $\operatorname{Sim}$ & $\mathrm{Sim}$ & $\mathrm{Sim}$ \\
Divisão do trabalho flexível & $\operatorname{Sim}$ & $\mathrm{Sim}$ & $\mathrm{Sim}$ \\
Disponibilizam treinamento para seus funcionários & Não & Sim & Não \\
Funcionários praticam apenas uma função & Não & Não & Não \\
\hline
\end{tabular}

Fonte: Os autores.

Observou-se que nas três citrícolas que a divisão do trabalho é flexível e dividido com coerência. $O$ procedimento de informação adotado para melhoria da qualidade utilizado pelas citrícolas é apenas a forma verbal. Importante ressaltar que a comunicação e a informação devem ser entendidas de maneira integral por parte dos colaboradores para que possua a construção de uma cultura de qualidade.

Mesmo sem disponibilizarem treinamento para seus funcionários e estes não praticam apenas uma função dentro da organização. A falta de treinamento pode comprometer o desenvolvimento da citrícola e afetar diretamente a qualidade dos produtos uma vez que o colaborador pode não possuir o devido conhecimento quanto aos critérios da empresa, produtos e processos. Além disso, as pessoas são partes mais importantes dentro de uma empresa, e os treinamentos devem ser uma realidade para a busca de melhoria contínua.

Conforme Cerqueira e Matias (1996), a gestão da qualidade envolve as ações de planejamento, de controle e de aprimoramento, a partir de políticas e objetivos estabelecidos pela direção. Requer organização e flexibilidade para poder servir como base de avaliação e aprimoramento contínuos dos produtos, processos e pessoas envolvidos. 
Os itens gerais aplicados para o diagnóstico dos métodos de melhoria contínua utilizados nas citrícolas de limões, e os respectivos resultados, estão apresentados na Tabela 2. Conforme os produtores, apenas dois dos três dizem ter conhecimento em gestão da qualidade.

Tabela 02. Itens gerais para identificação dos métodos de melhoria contínua usados nas citrícolas.

\begin{tabular}{lccc}
\hline \multirow{2}{*}{ Itens analisados } & \multicolumn{3}{c}{ Citrícola de limão } \\
\cline { 2 - 5 } & E1 & E2 & E3 \\
\hline Conhecimento em gestão de qualidade & Não & Sim & Sim \\
Pratica controle estatístico de processos (CEP)? & Não & Não & Não \\
Praticam amostragem estatística? & Não & Não & Não \\
Praticam a ferramenta 5S? & Não & Não & Não \\
Praticam a ferramenta Seis Sigma? & Não & Não & Não \\
Praticam a ferramenta Kaizen? & Não & Não & Não \\
Possuem a implementação do Kanban? & Não & Não & Não \\
Praticam a Manutenção Produtiva Total? & Sim & Sim & Sim \\
\hline
\end{tabular}

Fonte: Os autores.

Apenas um gestor de citrícola não possuía conhecimento sobre gestão da qualidade. A gestão da qualidade está relacionada como a abordagem adotada e o conjunto de sistemas, ferramentas e práticas planejadas e executadas pela empresa para obter, de forma eficiente e eficaz, a qualidade pretendida para o produto (TOLEDO, 2001).

Nas citrícolas não fazem usos de métodos de melhoria contínua, no entanto, a utilização de algum desses métodos, metas definidas, processo de qualidade, facilitariam muito os processos já existentes, e daria uma melhor visão e ajudaria a dar melhor direção para a citrícola conquistar novos mercados e aumentar seus rendimentos.

A exemplo, o programa $5 \mathrm{~S}$ estar completamente alinhado aos objetivos e procedimentos do programa de qualidade total, visando à melhoria contínua. Outra ferramenta de gestão é os Seis Sigmas que é definido como um processo de negócio que permite às organizações incrementar seus lucros por meio da otimização das operações, melhoria da qualidade e eliminação de defeitos, falhas e erros (HARRY; SCHROEDER, 1998).

A melhoria contínua baseada no sistema japonês Kaizen que significa melhoramento contínuo na organização e nas pessoas que lá trabalham, é uma abordagem evolutiva. Nesse conceito é sempre possível fazer melhor todo dia, por dia alguma melhoria deve ser implantada, seja na empresa ou no indivíduo. Comprometendo todos para busca de melhores resultados.

Para que a aplicação de métodos de melhoria contínua seja implantada, é necessária a criação de metas por parte da alta administração e a conscientização da mesma em ofertar produtos de melhor qualidade e ter melhores processos de padronização, uma vez que qualidade no ponto de vista do consumidor consiste de um produto atenda as necessidades dos clientes e que proporcione a satisfação com o produto adquirido.

Apesar de que ambas as empresas terem a preocupação com a qualidade dos seus produtos e processos, porém conforme a informação obtida observa-se que até mesmo a empresa com grande fluxo de produtos exportação, onde o grau de exigência em relação à qualidade para esses produtos são maiores que os destinados ao mercado brasileiro, não há aplicação de métodos de gestão da qualidade. 


\section{CONCLUSÃO}

O objetivo do trabalho foi alcançado com resultados para agregar conhecimento quanto à situação da utilização de métodos de melhoria contínua neste setor da agricultura.

A pesquisa mostra que os gestores possuem pouco ou nenhum conhecimento relacionados às ferramentas de gestão da qualidade.

Há necessidade de aplicação de um sistema de melhoria contínua nas citrícolas para proporcionar melhoria na qualidade do produto final, como também melhorar as práticas e procedimentos das atividades que compõem toda a cadeia produtiva, com o intuito de reduzir perdas, desperdícios e custos.

\section{REFERÊNCIAS}

CAMPOS, V. F. Qualidade Total: Padronização de empresas. 4.ed. Belo Horizonte: QFCO, 1991.

CARPINETTI, L. C. R. Gestão da qualidade. São Paulo: Atlas, 2012.

CERQUEIRA, J. P.; MARTINS, M. C. O sistema ISO 9000 na prática. São Paulo: ed. Pioneira, 1996.

MILOCA, L. M.; SAURIN, G.; STADUTO, J. A. R. O Processo de Coordenação de Cadeias Agroalimentares: Uma análise da Cadeia Produtiva da Mandioca no Paraná. Associação Brasileira dos Produtores de Amido de Mandioca, 2005.

TOLEDO, J.C., Gestão da qualidade na agroindústria, In: Batalha, M.O. (org), Gestão Agroindustrial, São Carlos: Ed. Atlas, 2001.

ZULIAN, A.; DÖRR, A. C.; ALMEIDA, S. C. Citricultura e agronegócio cooperativo no Brasil. Revista Eletrônica em Gestão, Educação e Tecnologia Ambiental, n. 11, p. 2290-2306, 2013. 